\title{
Critical assessment of different methods for quantitative measurement of metallodrug-protein associations
}

\author{
Luis Galvez ${ }^{1}$ - Sarah Theiner ${ }^{1}$ - Márkó Grabarics ${ }^{1} \cdot$ Christian R. Kowol $^{2} \cdot$ Bernhard K. Keppler $^{2}$ - Stephan Hann ${ }^{3}$. \\ Gunda Koellensperger ${ }^{1}$
}

Received: 2 May 2018 /Revised: 13 July 2018 / Accepted: 15 August 2018 / Published online: 29 August 2018

(C) The Author(s) 2018

\begin{abstract}
Quantitative screening for potential drug-protein binding is an essential step in developing novel metal-based anticancer drugs. ICP-MS approaches are at the core of this task; however, many applications lack in the capability of large-scale high-throughput screenings and proper validation. In this work, we critically discuss the analytical figures of merit and the potential method-based quantitative differences applying four different ICP-MS strategies to ex vivo drug-serum incubations. Two candidate drugs, more specifically, two Pt(IV) complexes with known differences of binding affinity towards serum proteins were selected. The study integrated centrifugal ultrafiltration followed by flow injection analysis, turbulent flow chromatography (TFC), and size exclusion chromatography (SEC), all combined with inductively coupled plasma-mass spectrometry (ICP-MS). As a novelty, for the first time, UHPLC SEC-ICP-MS was implemented to enable rapid protein separation to be performed within a few minutes at $>90 \%$ column recovery for protein adducts and small molecules.
\end{abstract}

Keywords Metal-based anticancer drugs $\cdot$ High-throughput $\cdot$ ICP-MS $\cdot$ Elemental speciation analysis $\cdot$ Metal-protein interaction

\section{Introduction}

The development of metal-based anticancer drugs continues to be a topical research theme. In fact, a recent upsurge of activities regards the development of metal-based compounds and non-classical platinum complexes whose mechanism of action is distinct from known drugs such as the clinically established cisplatin [1-3]. Many metal-based compounds have been synthesized by redesigning the existing chemical structure through ligand substitution or building the entire

Electronic supplementary material The online version of this article (https://doi.org/10.1007/s00216-018-1328-8) contains supplementary material, which is available to authorized users.

Gunda Koellensperger

gunda.koellensperger@univie.ac.at

1 Institute of Analytical Chemistry, Faculty of Chemistry, University of Vienna, Waehringer Strasse 38, 1090 Vienna, Austria

2 Institute of Inorganic Chemistry, Faculty of Chemistry, University of Vienna, Waehringer Strasse 42, 1090 Vienna, Austria

3 Department of Chemistry, Division of Analytical Chemistry, University of Natural Resources and Life Sciences - BOKU Vienna, Muthgasse 18, 1190 Vienna, Austria new compound with enhanced safety and cytotoxic profile $[3,4]$.

As in any drug development, studying the chemistry of the drug in solution-based ex vivo experiments is a first crucial step. In the case of metal-based anticancer drugs, in vitro protein binding studies received major attention, as it was recognized soon that protein binding occurred for many compounds already in short time scales in human blood and would be therefore decisive regarding drug delivery, drug deactivation, or vice versa drug activation. For example, whereas for platinum (II)-based drugs such as cisplatin binding to serum proteins, especially human serum albumin (HSA) leads to deactivation and lower bioavailability of the drug [5], other concepts exploit HSA for targeted drug delivery to the tumor tissue $[6,7]$. HSA is known to accumulate in cancer cells, an advantage that was investigated by the preparation of functionalized platinum (IV) prodrugs that were designed to bind selectively to HSA [8-10].

Evidently, tools of trade for this type of ex vivo investigations are offered by elemental speciation approaches utilizing ICP-MS as a detection technique of choice [11-14]. ICP-MS featuring species unspecific quantification capabilities was combined with intact-protein separation- or fractionation techniques ensuring native, i.e., mild chemical conditions, being 
the latter a prerequisite ensuring that protein binding was not reversed upon chromatographic separation, as drug protein association could be based on coordinative and/or covalent binding [3, 11, 15-19]. A comprehensive review about the different approaches is given elsewhere [20, 21]. In brief, capillary electrophoresis (CE) and SEC have been the most commonly applied native separation methods [22, 23]. Already in 1999 [24], SEC combined with ICP-MS emerged as essential tool for studying the interaction of metallodrugs and serum proteins and has seen numerous applications ever since in support of new drug design concepts. Despite this success, the separation was considered a low-resolution, timeconsuming method. The involved length of single experiments was regarded as major disadvantage especially when kinetics studies were addressed. Typical chromatographic separation times ranged between 20 and $30 \mathrm{~min}$ [25]. As an alternative to on-line separation, several studies resorted to an off-line fractionation technique, which had been developed in the late 1960s [26], namely centrifugal ultrafiltration using cut-off filters. As a key advantage, this strategy is technically very simple; however, it became very clear soon that filter material selection and preconditioning strategy was crucial regarding drug recovery [27-30], making this technique more tedious than expected. Flow injection (FI)-ICP-MS [28, 31] proved to be a valuable method addressing the metal-based drug distribution between low (LMF) and high molar mass fraction $(\mathrm{HMF})$ in very small sample volumes. In some cases, off-line protein removal was followed by LC-ICP-MS analysis in order to assess potential low molar mass transformation products of the metal-based drugs [16, 27, 32]. Only recently, on-line protein removal by turbulent flow chromatography (TFC) was introduced in combination with ICP-MS for studying metal-based anticancer drugs and their protein binding. TFC was first developed in the late 1990s as an emerging, alternative approach to study biological samples by extracting on-line the HMF and analyzing the LMF. In TFC, very high mobile phase linear velocities are combined with stationary phases consisting of large porous particles $(30-80 \mu \mathrm{m})$. This combination leads to a turbulent flow regime which generates a mass transfer cut-off allowing large molecules, e.g., proteins, to pass without any interaction. Small molecules can interact with the functional groups of the stationary phase and are then eluted subsequently by an appropriate solvent or buffer [33-36].

The aim of this work, thus, was to provide a comparison between different state-of-the-art methods focusing on the aspect of quantitative protein binding studies. The investigated approaches offered a varying degree of automation. The objective was to shed light on crucial and sometimes overlooked shortcomings that make a generalizable straightforward quantitative application without considering the chemistry of the metallodrugs difficult. Moreover, as a novelty, UHPLC SEC was combined with ICP-MS detection for studying metallodrug-protein interaction in human serum. Various approaches have been developed to improve the speed of sizeexclusion chromatography [37], with the recently introduced UHPLC SEC or sub-2 $\mu \mathrm{m}$ technique being one of the most promising ones, reducing both eddy dispersion and resistance towards mass transfer, two of the most important factors contributing to band broadening in liquid chromatography [38]. For SEC, these sub-2 $\mu \mathrm{m}$ materials have been introduced several years ago; however, their application in speciation studies is novel. A recent review reports on developments in UHPLC SEC [39] including the key application areas such as, e.g., purity monitoring of protein-related compounds in industry, the development process of biotherapeutic proteins, the field of proteomics, and the polymer industry [40, 41]. To the best of our knowledge, this technology has not been applied to speciation analysis with ICP-MS detection so far.

Despite the fact that numerous methods addressing metallodrug-biomolecule interactions are available, a comparative study on different metallodrugs (different ligand chemistry) is still lacking. Hence, next to size-exclusion-based approaches, the cross-validation study involved centrifugal filtration and turbulent flow chromatography, always in combination with ICP-MS detection. All investigated approaches were applied to test compounds in serum incubations. For this purpose, two platinum (IV)-based prodrugs (1) with selective albumin-binding properties by a maleimide moiety and (2) a negative control being non-reactive towards biomolecules with a succinimide moiety were selected. The novel drugs release oxaliplatin upon reductive activation. The compound with selective albumin binding was already tested in vivo colon carcinoma-bearing mice and treatment resulted in significantly reduced tumor growth and even disease stabilization. Additionally, for a very similar compound, a highly increased plasma half-life and very efficient tumor accumulation were observed [8].

\section{Experimental}

\section{Reagents, chemicals, and standards}

A reagent I grade water $\left(>10 \mathrm{M} \Omega \mathrm{cm}^{-1}\right.$ resistance according to ISO 3696 water specifications) purification system (Ultra Clear basic Reinstwassersystem, SG Wasseraufbereitung und Regenerierstation GmbH, Barsbüttel, Germany) was used to obtain purified water. Ammonium acetate ( $\geq 99 \%)$, glutathione disulfide ( $\geq 98 \%$ ), albumin from human serum (96-99\%), and myoglobine from equine skeletal muscle (95-100\%) were purchased from Sigma Aldrich, St. Louis, MO, USA. Methionine $(\geq 99 \%)$ was purchased from Merck (Darmstadt, Germany). Pt standard (1002 $\pm 6 \mu \mathrm{g} / \mathrm{mL})$ was purchased from Inorganic Ventures, Christiansburg, VA, USA. Fetal calf serum (FCS) was kindly provided by Prof. Walter Berger from 
<smiles></smiles>

KP2156

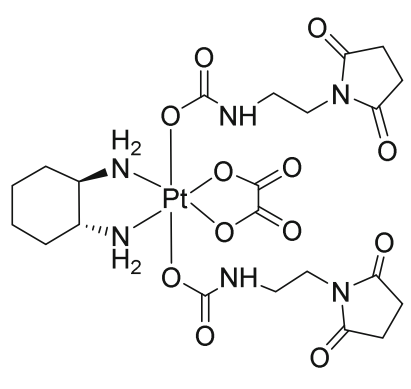

KP2157
Fig. 1 Chemical structures of KP2156 containing a maleimide moiety designed to bind covalently to the cystein residues of serum proteins via maleimide-thiol coupling reaction and KP2157 containing a succinimide moiety lacking of the ability to bind to sulfhydryl groups [8]

the Institute of Cancer Research, University of Vienna, Vienna, Austria. The analytical figures of merit for metallodrug studies were assessed by the use of two platinum (IV) compounds synthesized according to literature procedures [8] at the Institute of Inorganic Chemistry, University of Vienna, Vienna, Austria. The structures of these compounds, KP2156 and KP2157, are shown in Fig. 1. More specifically, the selection comprised KP2156 (trans-bis(2maleimideethylcarbamato)-dihydroxido(1R,2Rdiamminocyclohexane)-oxalatoplatinum (IV)), a maleimidefunctionalized Pt (IV) complex with oxaliplatin core and KP2157 (trans-bis(2-succinimideethylcarbamato)dihydroxido(1R,2R-diamminocyclohexane)-oxalatoplatinum (IV)), its succinimide analog [8]. While KP2156 is designed to bind covalently to the cystein residues of serum proteins via maleimide-thiol coupling reaction, in order to utilize the enhanced permeability and retention effect for targeting, its succinimide derivative, KP2157, inherently lacks the ability to form covalent bounds with sulfhydryl groups, due to the missing double bonds in the axial linker moiety (Fig. 1). Prior kinetics studies by UHPLC SEC in our laboratory showed this difference in the affinity towards serum proteins (see Electronic Supplementary Material (ESM) Table S1 for chromatography and ICP-MS conditions and Fig. S1 for chromatograms).

\section{Ex vivo incubations}

Stock solutions of KP2156 and KP2157 were prepared in water $(1 \mu \mathrm{M})$ right before the incubation in FCS. $100 \mu \mathrm{L}$ of the stock solution was incubated in $900 \mu \mathrm{L}$ of FCS (corresponding to a molar ratio of drug:albumin of 1:6000 approximately) for $45 \mathrm{~min}$ at $37^{\circ} \mathrm{C}$. Immediately prior to ICP-MS determination, the incubations were diluted by a factor of 10 resulting in a drug concentration of $0.01 \mu \mathrm{M}$. In all experiments, aqueous solutions of the drugs were employed, as the drugs are stable under these conditions [8].

\section{ICP-MS}

The ICP-MS instrument used for the quantification studies with conventional SEC and TFC was an iCAP-QMS Thermo Scientific (Bremen, Germany) with oxygen (purity 5.0, Linde Gas GmbH, Vienna, Austria) as reaction gas and Qtegra Intelligent Scientific Data Solution (version 2.4.1800.33) for the data treatment. For the quantification in the centrifugal ultrafiltration studies and for UHPLC SEC, the Agilent 8800 ICP-MS/MS (Agilent Technologies, Tokyo, Japan) was used with Agilent MassHunter software package (Work- station Software, Version C.01.03, 2016) for the data treatment. The ICP-MS parameters are summarized in Table 1.

\section{SEC and UHPLC SEC}

The Agilent 1260 infinity Bio-inert HPLC system (Agilent Technologies, Waldbronn, Germany) was employed for the UHPLC SEC measurements. For the quantification studies with conventional SEC, the Thermo Scientific Transcend HPLC system (San Jose, CA, USA) was used. The chromatographic conditions are given in Table 2.

\section{Centrifugal ultrafiltration}

Centrifugal ultrafiltration was carried out using Amicon Ultra $0.5-\mathrm{mL}$ centrifugal regenerated cellulose membrane filters,
Table 1 ICP-MS operation parameters

\begin{tabular}{lll}
\hline Instrumentation ICP-MS & iCAP-QMS Thermo Scientific & ICP-MS/MS Agilent 8800 \\
\hline Nebulizer & PFA-ST & MicroMist \\
Spray chamber & Cyclonic & Scott double-pass \\
Nebulizer gas flow & $1.01 \mathrm{~L} / \mathrm{min}$ & $1.05 \mathrm{~L} / \mathrm{min}$ \\
Aux. gas & $0.99 \mathrm{~L} / \mathrm{min}$ & $0.90 \mathrm{~L} / \mathrm{min}$ \\
Plasma gas & $14 \mathrm{~L} / \mathrm{min}$ & $15 \mathrm{~L} / \mathrm{min}$ \\
Reaction gas & $0.370 \mathrm{~mL} / \mathrm{min}$ & $0.300 \mathrm{~mL} / \mathrm{min}$ \\
ICP RF Power & $1550 \mathrm{~W}$ & $1550 \mathrm{~W}$ \\
m/z measured & $194.97,47.97$ & 195,48
\end{tabular}


Table 2 Chromatographic conditions

\begin{tabular}{|c|c|c|}
\hline $\begin{array}{l}\text { Instrumentation } \\
\text { HPLC }\end{array}$ & Agilent 1260 infinity Bio-inert & $\begin{array}{l}\text { Thermo Scientific } \\
\text { Transcend system }\end{array}$ \\
\hline HPLC Column & $\begin{array}{l}\text { Acquity UPLC Protein } \\
\text { BEH SEC, } 4.6 \times 150 \mathrm{~mm} \text {, } \\
125 \mathrm{~A}, 1.7 \mu \mathrm{m}, 1 \mathrm{kDa}-80 \\
\text { kDa, Waters }\end{array}$ & $\begin{array}{l}\text { BioBasic SEC-60 A, } \\
4.6 \times 250 \mathrm{~mm}, 5 \mu \mathrm{m}, \\
0.1 \mathrm{kDa}-10,000 \\
\mathrm{kDa} \text { Thermo }\end{array}$ \\
\hline Eluent & $50 \mathrm{mM} \mathrm{CH}_{3} \mathrm{COONH}_{4}, \mathrm{pH}=6.0$ & $\begin{array}{c}50 \mathrm{mM} \mathrm{CH}_{3} \mathrm{COONH}_{4} \\
\mathrm{pH}=6.0\end{array}$ \\
\hline Flow rate & $400 \mu \mathrm{L} / \mathrm{min}$ & $250 \mu \mathrm{L} / \mathrm{min}$ \\
\hline Injection volume & $5 \mu \mathrm{L}$ & $10 \mu \mathrm{L}$ \\
\hline Column temperature & $30^{\circ} \mathrm{C}$ & Room temperature \\
\hline Autosampler Temperature & $4{ }^{\circ} \mathrm{C}$ & $4{ }^{\circ} \mathrm{C}$ \\
\hline Combined with & ICP-MS/MS Agilent 8800 & $\begin{array}{l}\text { ICP-QMS iCAP } \\
\text { Thermo Scientific }\end{array}$ \\
\hline
\end{tabular}

with a 10-kDa molecular weight cut-off (MWCO) (Millipore Co, Carrigtwohill, Co. Cork, Ireland). The samples were ultracentrifuged with a Hermle Z $466 \mathrm{~K}$ device with a precooled rotor $\left(4^{\circ} \mathrm{C}\right)$ at a $\mathrm{G}$-force of $12,500 \mathrm{~g}$. For preconditioning of the membrane filters and ultracentrifugation of the drug solutions, a centrifugation time of $60 \mathrm{~min}$ and $15 \mathrm{~min}$ was used, respectively. The filters used for centrifugal ultrafiltration were preconditioned using the solvents with the highest recovery for the drugs, respectively. For KP2156, $50 \mathrm{mM} \mathrm{CH}_{3} \mathrm{COONH}_{4}, \mathrm{pH}=6.0$ was employed, whereas for KP2157 FCS was used. Flow injection measurements for platinum quantification were performed using an Agilent 1260 Infinity Bio-inert HPLC system (Agilent Technologies, Waldbronn, Germany) coupled to an Agilent 8800 ICP-MS/

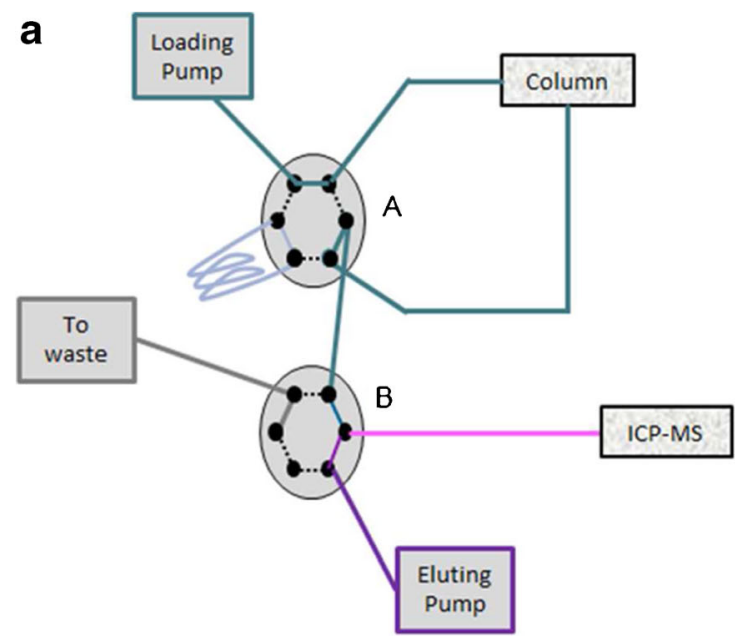

Fig. 2 A At turbulent flow conditions ( $1 \mathrm{~mL} / \mathrm{min}, 20 \% \mathrm{MeOH}$, delivered by the loading pump, while the eluting pump is set to $0 \mathrm{~mL} / \mathrm{min}$ flow), the HMF (bound fraction of metallodrug) shows no retention on the column and can hence be directed to the ICP-MS (depending on the valve B position). The free drug corresponding to the low molar mass fraction LMF is retained. Subsequently, the flow delivered by the loading pump is reduced to $0.2 \mathrm{~mL} / \mathrm{min}(20 \% \mathrm{MeOH})$ and mixed with the flow delivered by the eluting pump $(0.8 \mathrm{~mL} / \mathrm{min} 100 \%$ buffer $)$. In the following step, the valve A is switched (B) and the "loading pump"- eluent, mixed with a
MS (Agilent Technologies, Tokyo, Japan). The HPLC system was operated with $\mathrm{CH}_{3} \mathrm{COONH}_{4}(50 \mathrm{mM}, \mathrm{pH}=6)$ as eluent, a flow rate of $250 \mu \mathrm{L} / \mathrm{min}$, and an injection volume of $10 \mu \mathrm{L}$. The ICP-MS operation parameters are summarized in Table 1.

\section{TFC}

TFC combines SEC and traditional stationary phase chemistry. In this case, a reversed phase was employed. The HPLC used was a HPLC Thermo Scientific Transcend system (San Jose, CA, USA) coupled to an ICP-QMS iCAP Thermo Scientific (Bremen, Germany). The separation and elution of the HMF and LMF were carried out by a two inert six-port

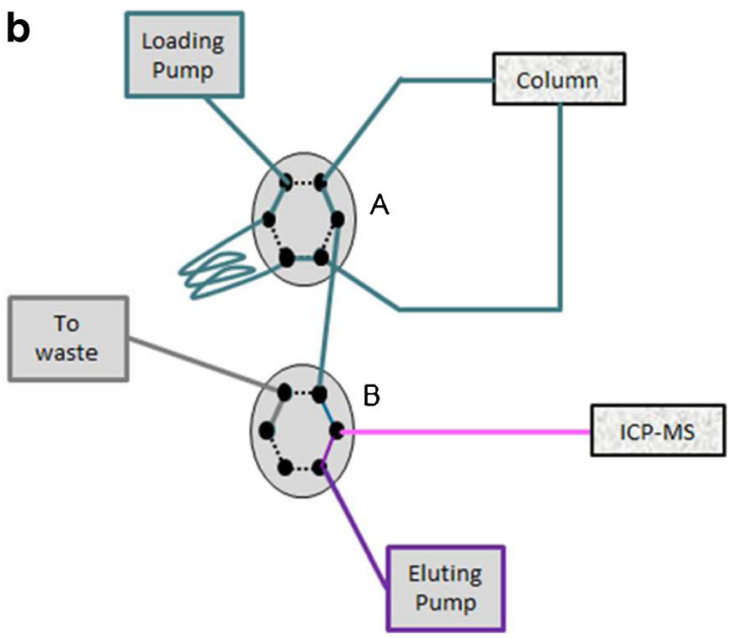

solvent plug of $100 \% \mathrm{MeOH}$ in a loop, is sent back-flush to the column. This high organic solvent conditions $(0.2 \mathrm{~mL} / \mathrm{min})$ result in elution of the LMF from the column. Before reaching the ICP-MS, the latter flow is combined with the flow of the eluting pump, in order to reduce the $\mathrm{MeOH}$ content. Throughout all steps, the flow rate entering the introduction system of the ICP-MS is set to $1 \mathrm{~mL} / \mathrm{min}$. Finally, the last steps involve column cleaning and the loop loading with $100 \% \mathrm{MeOH}$. In the last step, the valve $\mathrm{A}$ is switched to the initial position (A) and the column is preconditioned for the next injection 
Table 3 Chromatographic conditions and TFC method

$\begin{array}{ll}\text { Chromatographic conditions } & \\ \text { HPLC Column } & \text { Fluoro XL } 0.5 \times 50 \mathrm{~mm} \\ \text { Eluent } & \text { Eluent B } 50 \mathrm{mM} \mathrm{CH}_{3} \mathrm{COONH}_{4}, \mathrm{pH}=6.0 \text {, Eluent C MeOH } \\ \text { Injection volume } & 10 \mu \mathrm{L} \\ \text { Column temperature } & \text { Room temperature } \\ \text { Autosampler temperature } & 4{ }^{\circ} \mathrm{C}\end{array}$

TFC Method

\begin{tabular}{|c|c|c|c|c|c|c|c|c|c|c|c|c|c|c|c|c|}
\hline \multirow[t]{2}{*}{ Step } & \multirow[t]{2}{*}{ Start } & \multirow[t]{2}{*}{$\mathrm{Sec}$} & \multicolumn{6}{|c|}{ Loading pump } & \multirow[t]{2}{*}{ Tee } & \multirow[t]{2}{*}{ Loop } & \multicolumn{6}{|c|}{ Eluting pump } \\
\hline & & & Flow & Grad & A & $\mathrm{B}$ & $\mathrm{C}$ & $\mathrm{D}$ & & & Flow & Grad & A & $\mathrm{B}$ & $\mathrm{C}$ & $\mathrm{D}$ \\
\hline 1 & 0 & 40 & 1 & Step & - & 80 & 20 & - & $\mathrm{T}$ & out & 0 & step & - & 80 & 20 & - \\
\hline 2 & 0.67 & 5 & 0.2 & Step & - & 80 & 20 & - & $\mathrm{T}$ & out & 0.8 & step & - & 100 & - & - \\
\hline 3 & 0.75 & 55 & 0.2 & Step & - & 80 & 20 & - & $\mathrm{T}$ & in & 0.8 & step & - & 100 & - & - \\
\hline 4 & 1.67 & 10 & 1 & Step & - & - & 100 & - & $===$ & in & 1 & step & - & 80 & 20 & - \\
\hline 5 & 1.83 & 200 & 1 & Step & - & - & 100 & - & $===$ & in & 1 & step & - & 80 & 20 & - \\
\hline 6 & 5.17 & 240 & 1 & Step & - & 80 & 20 & - & $===$ & out & 1 & step & - & 80 & 20 & - \\
\hline
\end{tabular}

valves present in this HPLC instrument (Fig. 2). The chromatographic conditions and the method are shown in Table 3.

\section{Results and discussions}

\section{SEC and UHPLC SEC}

The UHPLC SEC-ICP-MS approach established in this work relied on the most advanced columns available on the market. More specifically, the implemented SEC column was based on the use of high pore-volume ethylene-bridged hybrids (BEH) particles with diol-bonded surface which combines an increase of $\sim 75 \%$ in pore volume with the required mechanical rigidity to maintain their integrity under high pressure and shear conditions. This stationary phase shows significantly reduced acidity of residual silanol groups, thereby reducing the contribution of unwanted ionic interaction between separated molecules and the stationary phase. UHPLC SEC when compared to conventional SEC for methionine (see ESM Table S2), (compound selection based on comparable retention time factors on the two columns) showed significantly higher separation efficiency. In fact, the number of theoretical plates/m was increased drastically, due to smaller peak widths. Figure 3A, B shows typical UHPLC SEC-ICP-MS separations accomplished within a few minutes. The size ladder consisting of a protein/amino acid mixture (Fig. 3A) and undiluted FCS (Fig. 3B) was analyzed monitoring sulfur $(\mathrm{m} / \mathrm{z}$ 47.97 with oxygen as reaction gas). The retention time of the most abundant protein in FCS corresponded to albumin

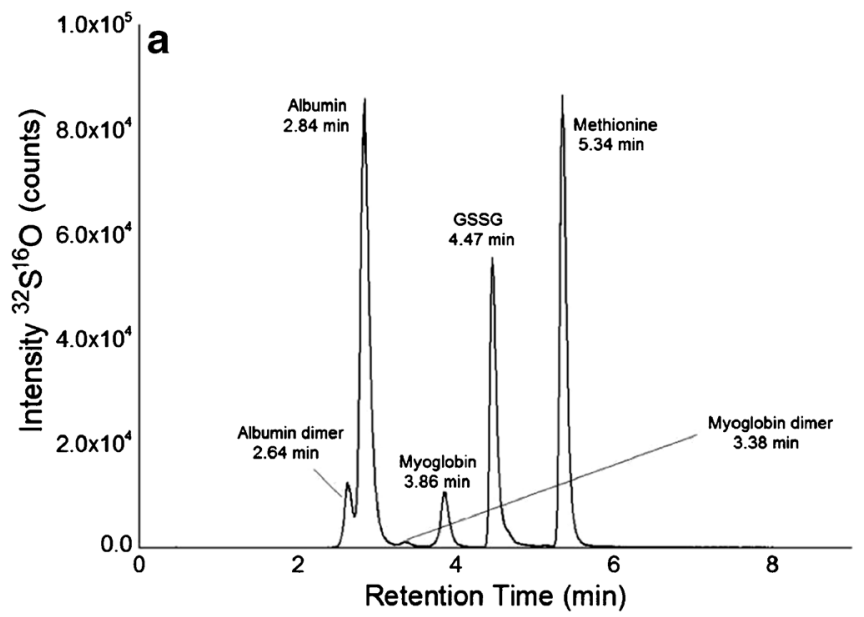

Fig. 3 UHPLC SEC chromatograms with the column Acquity UPLC Protein BEH SEC, $4.6 \times 150 \mathrm{~mm}, 125 \mathrm{~A}, 1.7 \mu \mathrm{m}$, size range $1 \mathrm{kDa}-$ $80 \mathrm{kDa}$, at a flow rate of $400 \mu \mathrm{L} / \mathrm{min}$ and an injection volume of $5 \mu \mathrm{L}$ of (A) a protein/amino acid mixture containing standards of HSA

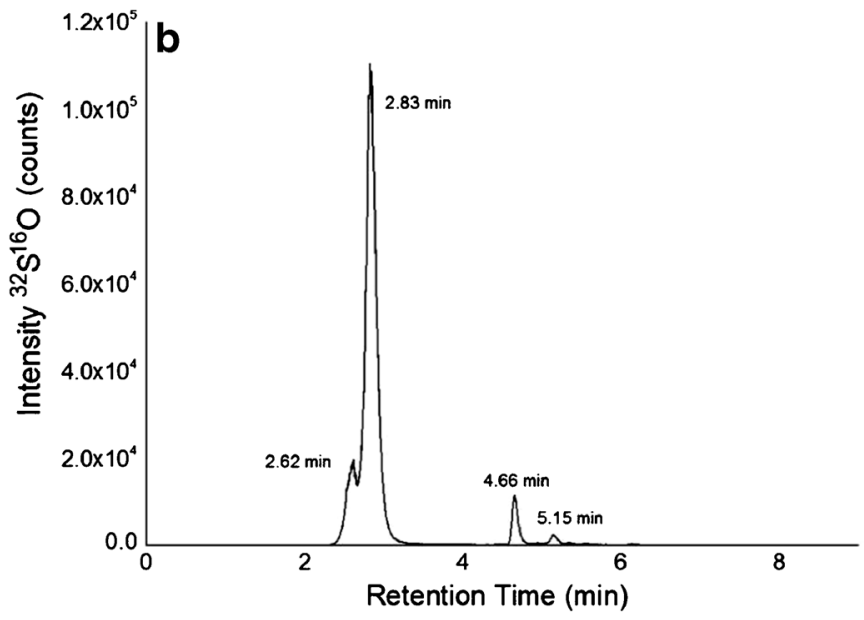

$(66 \mathrm{kDa})(\sim 9.32 \mu \mathrm{M})$, Myoglobin $(17 \mathrm{kDa})(\sim 34.6 \mu \mathrm{M})$, glutathione disulfide (GSSG, $0.6 \mathrm{kDa})(\sim 375 \mu \mathrm{M})$ and methionine $(0.1 \mathrm{kDa})(\sim$ $1700 \mu \mathrm{M})$ and (B) undiluted FCS. Sulfur was monitored as ${ }^{32} \mathrm{~S}^{16} \mathrm{O}$ at $\mathrm{m} / \mathrm{z} 47.97$ with oxygen as reaction gas 
Table 4 Analytical figures of merit of the standards and the samples

\begin{tabular}{lllll} 
Acquity UPLC Protein BEH SEC, $4.6 \times 150 \mathrm{~mm}, 125 \mathrm{~A}, 1.7 \mu \mathrm{m}$ & \\
\hline Compound & $\begin{array}{l}\text { Recovery } \\
(\%)\end{array}$ & $\begin{array}{l}\text { LOD }(\mathrm{nM}) \\
3 \sigma \text { criterion }\end{array}$ & $\begin{array}{l}\text { LOD }(\mu \mathrm{g} / \mathrm{L} \mathrm{Pt}) \\
3 \sigma \text { criterion }\end{array}$ & $\begin{array}{l}\text { Absolute LOD (fg Pt) } \\
3 \sigma \text { criterion }\end{array}$ \\
\hline KP2156 & $100 \pm 5$ & 0.50 & 0.10 & 500 \\
KP2157 & $99 \pm 9$ & 0.51 & 0.10 & 500 \\
KP2156 in serum & $101 \pm 4$ & 0.71 & 0.14 & 700 \\
KP2157 in serum & $97 \pm 3$ & 0.36 & 0.07 & 350 \\
\hline
\end{tabular}

(2.83 min). The optimal size range of the used column was 1$80 \mathrm{kDa}$, presenting thus, the dimer of albumin (132 kDa) in the exclusion limit/void volume (2.64 $\mathrm{min})$.

The analytical figures of merit for metallodrug studies were assessed by the use of KP2156 and KP2157 which served as perfect structural analogs of each other, with significantly different affinity towards serum proteins as explained in the experimental part and shown in the ESM (Table S1 and Fig. S1).

As can be readily seen in Table 4, UHPLC SEC-ICP-MS resulted in excellent recoveries for Pt. Regardless whether drug serum incubations (45 min of incubation of KP2156 and $\mathrm{KP} 2157$ in $\mathrm{FCS}$ at $37^{\circ} \mathrm{C}$, resulting in a molar ratio of drug:albumin of $\sim 1: 6000)$ or drug only $(0.01 \mu \mathrm{M})$ was analyzed, the mass balance for Pt was complete as the diol bonded surface of the porous hybrid organic/inorganic particles featured significantly decreased acidity of the residual silanol groups. In this way, the SEC eluent composition could be optimized with the aim of reducing salt content thereby increasing the robustness of the method without compromising protein or small molecule recovery. Moreover, excellent limits of detection could be obtained which were comparable to conventional SEC (Table 7), despite the fact that the latter approach utilized lower flow rates (by a factor of 2) and higher injection volumes (factor of 2). Excellent intermediate repeatabilities of $2 \%$ were observed for UHPLC SEC-ICP-MS (flow rate of $400 \mu \mathrm{L} / \mathrm{min}$ and an injection volume of $5 \mu \mathrm{L}$ ) upon $n=18$ and $n=15$ injections over $24 \mathrm{~h}$ for albumin

Table 5 Centrifugal ultrafiltration

\begin{tabular}{lll} 
Standards $(0.1 \mu \mathrm{M})$ & \\
\hline Compound & Preconditioning & Recovery (\%) \\
\hline KP2156 & - & $8.7 \pm 1.1 n=3$ \\
KP2156 & Milli-Q water & $10 \pm 1 n=3$ \\
KP2156 & $50 \mathrm{mM} \mathrm{CH}_{3} \mathrm{COONH}_{4}, \mathrm{pH}=6.0$ & $9.6 \pm 2.1 n=3$ \\
KP2156 & FCS & $7.5 \pm 1.4 n=3$ \\
KP2157 & - & $38 \pm 2 n=9$ \\
KP2157 & Milli-Q water & $41 \pm 3 n=9$ \\
KP2157 & $50 ~ \mathrm{mM} \mathrm{CH}_{3} \mathrm{COONH}_{4}, \mathrm{pH}=6.0$ & $38 \pm 6 n=9$ \\
KP2157 & FCS & $60 \pm 3 n=9$ \\
\hline
\end{tabular}

(monitored via sulfur) and a serum incubation of KP2156 (monitored via $\mathrm{Pt}$ ). The chromatographic retention time repeatability ranged at 0.4 and $0.5 \%$ respectively.

\section{Centrifugal ultrafiltration}

An orthogonal approach to SEC and UHPLC SEC-ICP-MS suitable to ex vivo screening of metallodrug-protein interaction is offered by centrifugal ultrafiltration. The sample is fractionated into a protein rich high molar mass fraction (HMF) and a filtrate which constitutes the low molar mass fraction (LMF). The established procedure is to analyze the total Pt content of the sample prior to fractionation, followed by the determination of the Pt content of the filtrate. Due to practical reasons, the HMF is derived from the difference of the two obtained $\mathrm{Pt}$ amounts provided that the mass balance of the procedure is complete. Although it could seem a straightforward method, the often encountered poor recoveries of the metal-based drugs pose sever limitations to this otherwise simple method. As the quantitative results critically depend on filter materials [27-30] and preconditioning, we evaluated different preconditioning strategies for the two test compounds KP2156 and KP2157 (Table 5). Regenerated cellulose filters with a cut-off limit of $10 \mathrm{kDa}$ were selected as these filters showed excellent recoveries for different $\mathrm{Pt}(\mathrm{II})$ compounds [27]. In this study, regardless which preconditioning method was tested, the recovery of the free drug from diluted drug standards was poor. However, the obtained LODs were lower by a factor of 10 compared to the SEC strategy. The LODs ranged at $0.03 \mathrm{nM}(0.006 \mu \mathrm{g} / \mathrm{L}$ of $\mathrm{Pt})$ and $0.01 \mathrm{nM}$ $(0.002 \mu \mathrm{g} / \mathrm{L}$ of $\mathrm{Pt})$ for KP2156 and KP2157, respectively ( $3 \sigma$ criterion).

\section{TFC-ICP-MS}

TFC has appeared more recently as an on-line extraction technique to study metallodrug-protein interactions, where the protein rich HMF is removed on-line by utilizing TFC. In essence, the two fractions HMF and LMF can be analyzed only considering their Pt content or alternatively, in a more sophisticated approach, the LMF is analyzed on a second analytical column [33-36]. TFC columns are available in 

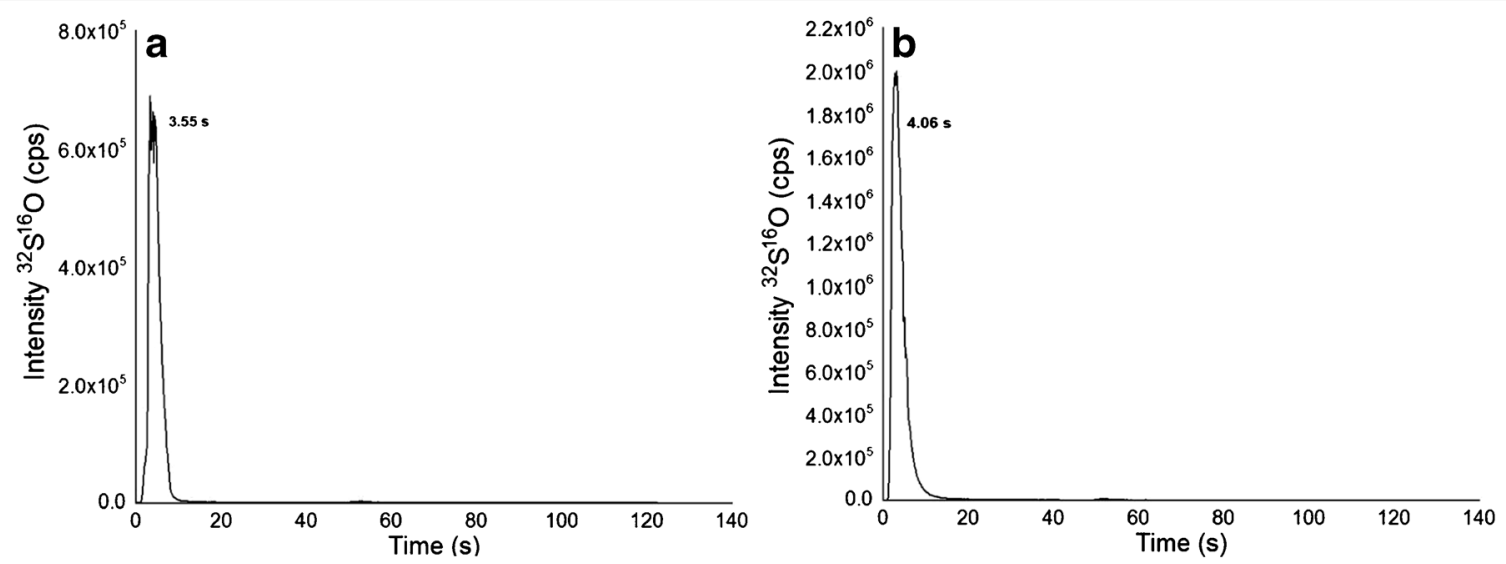

Fig. 4 TFC chromatograms of (A) a standard of albumin $3.79 \mathrm{nM}$. The LOD was $0.006 \mathrm{nM}$ ( $3 \sigma$ criterion). B FCS diluted 1:10 in water. Sulfur was monitored at $\mathrm{m} / \mathrm{z} 48$ with oxygen as reaction gas

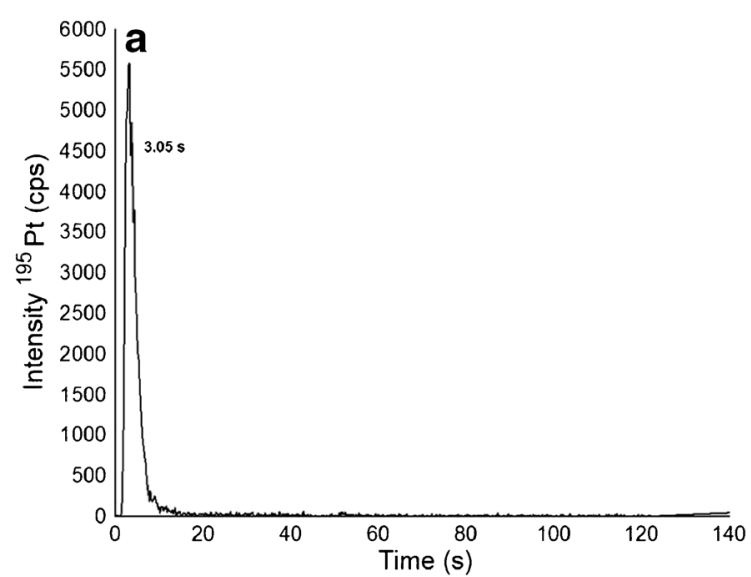

Fig. 5 TFC chromatograms of (A) an incubation of KP2156 $0.1 \mu \mathrm{M}$ $\left(20 \mu \mathrm{g} / \mathrm{L}\right.$ of Pt) $1: 10$ in FCS during $45 \mathrm{~min}$ at $37^{\circ} \mathrm{C}$ and diluted $1: 10$ in water prior to the analysis (B) an incubation of KP2157 $0.1 \mu \mathrm{M}(20 \mu \mathrm{g} / \mathrm{L}$

different chemistries and dimensions [42, 43]. In this work, a silica-based fluorinated alkyl stationary phase was employed which provided a unique selectivity compared to other reversed phase chemistries [43]. TFC is a rapid analytical process compared to SEC; however, the duty cycle between samples is 9 min due to loop filling and preconditioning of the TFC column (Fig. 2). Overall, comparable throughput to UHPLC SEC could be achieved, but at the expense of higher solvent consumption necessary to reach the turbulent conditions. Figure 4 shows the TFC-ICP-MS analysis of albumin and FCS, where the protein shows virtually no retention.

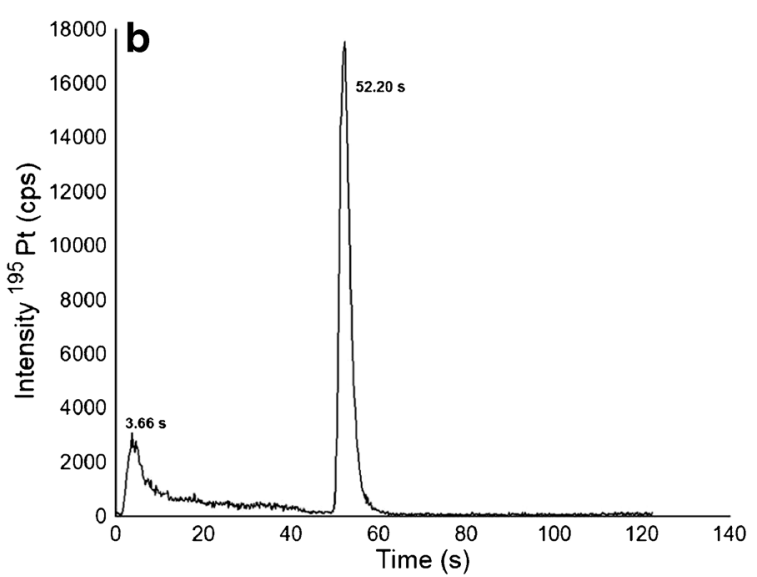

of Pt) 1:10 in FCS during $45 \mathrm{~min}$ at $37^{\circ} \mathrm{C}$ and diluted $1: 10$ in water prior to the analysis. Pt was monitored at $\mathrm{m} / \mathrm{z} 195$

Figure 5 shows the results from the incubations of KP2156 and KP2157 with serum. In accordance with the fact that KP2156 shows pronounced protein binding, no retention for Pt was observed. Only the free KP2157 showed retention. The free drug (52.2 s) was retained on the column until the back flushing with $\mathrm{MeOH}$ was applied. TFC-ICP-MS analysis revealed two peaks for KP2157 which could be explained by the occurrence of KP2157 protein adducts and/or the generation of a hydrophilic hydrolysis product of KP2157 showing no reversed phase retention on the TFC stationary phase. The latter explanation is in accordance with UHPLC SEC-ICP-
Table 6 Analytical figures of merit of the standards and the samples

\begin{tabular}{llllll}
\hline Compound & $\begin{array}{l}\text { Recovery } \\
(\%) n=3\end{array}$ & $\begin{array}{l}\text { Precision } \\
(\%) n=3\end{array}$ & $\begin{array}{l}\text { LOD }(\mathrm{nM}) 3 \sigma \\
\text { criterion }\end{array}$ & $\begin{array}{l}\text { LOD }(\mu \mathrm{g} / \mathrm{L} \mathrm{Pt}) \\
3 \sigma \text { criterion }\end{array}$ & $\begin{array}{l}\text { Absolute LOD (fg Pt) } \\
3 \sigma \text { criterion }\end{array}$ \\
\hline KP2157 & $85 \pm 3$ & 2 & 0.04 & 0.008 & 80 \\
KP2156 & $54 \pm 1$ & 5 & 0.05 & 0.01 & 100 \\
KP2156 in FCS & $64 \pm 2$ & 1 & 0.03 & 0.006 & 60 \\
KP2157 in FCS & $90 \pm 5$ & 7 & 0.04 & 0.008 & 80 \\
\hline
\end{tabular}


MS measurements revealing the presence of low molar mass transformation products. As can be observed in Table 6, the TFC approach provided excellent LODs in the sub $\mathrm{nM}$ range. As a drawback, the drug recoveries and repeatabilities were compromised compared to the UHPLC SEC-ICP-MS analysis.

\section{Cross-validation of SEC-ICP-MS, UHPLC SEC-ICP-MS, TFC-ICP-MS, and centrifugal ultrafiltration}

Finally, the discussed methods were compared regarding their suitability of quantifying the degree of protein metallodrugadduct formation. KP2156 and KP2157 $(0.1 \mu \mathrm{M}, 20 \mu \mathrm{g} / \mathrm{L}$ of t) were incubated in fetal calf serum for $45 \mathrm{~min}$ at $37^{\circ} \mathrm{C}$, corresponding to a molar ratio of drug:albumin of approximately 1:6000. The incubation solutions were analyzed by conventional size-exclusion (optimal size range $0.1 \mathrm{kDa}-$ 10,000 kDa), (see ESM Fig. S2) by UHPLC SEC-ICP-MS (optimal size range of 1-80 kDa), (see ESM Fig. S3) by centrifugal ultrafiltration combined with flow injection analysis and finally, by TFC-ICP-MS (Fig. 5). While for the SEC- and centrifugal ultrafiltration-based methods, standard dilutions of one Pt(IV) compound served for calibration of all investigated $\mathrm{Pt}(\mathrm{IV})$ drugs and protein adducts, this species-unspecific quantification concept could not be expanded to the TFC methodology without considering the fact that the high molar mass fraction and the retained hydrophobic low molar mass fraction eluted under completely different conditions from the
TFC column. Fig. S4 in the ESM shows the TFC measurements of the established calibration strategy.

Table 7 summarizes the most important findings of the cross-validation study. KP2157 was assessed in the LMF by calibration using a dilution series of the drugs. However, since Pt was < LOD in the HMF, for all methods except in TFCICP-MS, the bound Pt was assessed by difference to the total Pt measured by FI-ICP-MS. The opposite was true for KP2156. In this case, Pt adducts were actually quantified while the LMF was assessed as difference of the experimentally assessed Pt adduct to the total Pt. While SEC-ICP-MS and UHPLC SEC-ICP-MS were in excellent agreement for both quantification exercises, the values obtained by ultrafiltration and TFC-ICP-MS revealed inconsistencies. The former approach was compromised by poor recoveries of the free $\mathrm{Pt}(\mathrm{IV})$ compounds. Therefore, correction for recovery resulted in biased values regarding the degree of protein binding of KP2156. While with all other approaches, the LMF fraction of KP2156 was < LOD upon incubation in serum, in ultrafiltration a LMF fraction of $38 \%$ was found. TFC-ICP-MS resulted in a biased quantification in the case of KP2157. Here, a low molar mass product co-eluted with the protein fraction.

\section{Conclusions}

Different speciation methods were investigated regarding their screening capabilities towards protein binding of

Table 7 Findings of the cross-validation study

\begin{tabular}{|c|c|c|c|c|}
\hline Results & SEC & UHPLC SEC & Centrifugal ultrafiltration & TFC \\
\hline Sample Preparation & No & No & Yes $(1.25 \mathrm{~h})$ & No \\
\hline Time of Analysis & $30 \mathrm{~min} / \mathrm{sample}$ & $7 \mathrm{~min} / \mathrm{sample}$ & $1 \mathrm{~min} / \mathrm{sample}$ & $9 \mathrm{~min} / \mathrm{sample}$ \\
\hline Solvent consumption & Medium & Medium & Low & High \\
\hline Recovery (\%) KP2157 & $93 \pm 3$ & $97 \pm 3$ & $60 \pm 3^{\mathrm{a}}$ & $90 \pm 5$ \\
\hline Recovery (\%) KP2156 & $96 \pm 1$ & $101 \pm 4$ & $9.6 \pm 2.1^{\mathrm{a}}$ & $64 \pm 2$ \\
\hline $\mathrm{LOD}(\mu \mathrm{g} / \mathrm{L} \mathrm{Pt})(3 \sigma$ criterion $)$ & $0.04-0.16$ & $0.07-0.14$ & $0.003-0.004$ & $0.006-0.01$ \\
\hline \multicolumn{5}{|l|}{ Assessed by calibration } \\
\hline KP2157 in the LMF (\%) & $96 \pm 2, n=3$ & $93 \pm 2, n=3$ & $95 \pm 4 \mathrm{~b}, n=9$ & $74 \pm 4, n=3$ \\
\hline KP2157 in the HMF (\%) & - & - & - & $38 \pm 11, n=3$ \\
\hline KP2156 in the LMF (\% & - & - & $38 \pm 6^{\mathrm{b}}, n=3$ & - \\
\hline KP2156 in the HMF (\%) & $102 \pm 1, n=3$ & $98 \pm 4, n=3$ & - & $98 \pm 3, n=3$ \\
\hline \multicolumn{5}{|l|}{ Assessed by difference } \\
\hline KP2157 in the LMF (\%) & - & - & - & - \\
\hline KP2157 in the HMF (\%) & $3.6 \pm 1.9, n=3$ & $6.9 \pm 2.5, n=3$ & $4.6 \pm 4.4^{\mathrm{b}}, n=9$ & $26 \pm 4, n=3$ \\
\hline KP2156 in the LMF (\%) & $-\mathrm{c}$ & $-\mathrm{c}$ & - & $-\mathrm{c}$ \\
\hline $\mathrm{KP} 2156$ in the HMF (\%) & - & - & $62 \pm 6^{\mathrm{b}}, \mathrm{n}=3$ & - \\
\hline
\end{tabular}

${ }^{a}$ Corresponding to the standards of the drugs in water

${ }^{\mathrm{b}}$ Using the preconditioning method with the best recoveries: $50 \mathrm{mM} \mathrm{CH} 3 \mathrm{COONH} 4, \mathrm{pH}=6.0$ and FCS for KP2156 and KP2157 respectively (see Table 5)

${ }^{\mathrm{c}}$ Below the uncertainty 
metallodrugs. Among the techniques, the analytical performance of the UHPLC SEC-ICP-MS suited best to perform such studies in a high-throughput manner as required in preclinical drug development without the necessity of finding dedicated analysis conditions upon investigating drugs with very different protein-binding affinity.

Acknowledgements Open access funding provided by Austrian Science Fund (FWF). We acknowledge Thermo Scientific for providing the turbulent flow separation columns and Dr. Josef Mayr for the synthesis of KP2156 and KP2157. FCS provided by Prof. Walter Berger is gratefully acknowledged.

Funding information We acknowledge the Austrian Science Fund (P26603) for financial support.

\section{Compliance with ethical standards}

Conflict of interest The authors declare that they have no conflict of interest.

Open Access This article is distributed under the terms of the Creative Commons Attribution 4.0 International License (http:// creativecommons.org/licenses/by/4.0/), which permits unrestricted use, distribution, and reproduction in any medium, provided you give appropriate credit to the original author(s) and the source, provide a link to the Creative Commons license, and indicate if changes were made.

\section{References}

1. Heffeter P, Böck K, Bartel C. Intracellular protein binding patterns of the anticancer ruthenium drugs KP1019 and KP1339. J Biol Inorg Chem. 2012; https://doi.org/10.1007/s00775-010-0642-1.

2. Trondl R, Hefferter P, Kowol CR, Jakupec MA, Berger W, Keppler BK. NKP-1339, the first ruthenium-based anticancer drug on the edge to clinical application. Chem Sci. 2014; https://doi.org/10. 1039/C3SC53243G.

3. Groessl M, Hartinger CG. Anticancer metallodrug research analytically painting the "omics" picture - current developments and future trends. Anal Bioanal Chem. 2013; https://doi.org/10.1007/ s00216-012-6450-4.

4. Che C, Sun RW. Therapeutic applications of gold complexes: lipophilic gold (III) cations and gold (I) complexes for anti-cancer treatment. Chem Commun. 2011; https://doi.org/10.1039/c1cc10860c.

5. Gibson D. The mechanism of action of platinum anticancer agents - what do we really know about it? Dalton Trans. 2009; https://doi.org/10.1039/B918871C.

6. Garmann D, Warnecke A, Kalayda GV, Kratz F, Jaehde U. Cellular accumulation and cytotoxicity of macromolecular platinum complexes in cisplatin-resistant tumor cells. J Control Release. 2008; https://doi.org/10.1016/j.jconrel.2008.07.017.

7. Larsen MT, Kuhlmann M, Hvam ML, Howard KA. Albumin-based drug delivery: harnessing nature to cure disease. Mol Cell Ther. 2016; https://doi.org/10.1186/s40591-016-0048-8.

8. Pichler V, Mayr J, Heffeter P, Dömötör O, Enyedy EA, Hermann G, et al. Maleimide-functionalised platinum (IV) complexes as a synthetic platform for targeted drug delivery. Chem Commun. 2013; https://doi.org/10.1039/c3cc39258a.

9. Zheng Y, Suntharalingam K, Johnstone TC, Yoo H, Lin W, Brooks $\mathrm{JG}$, et al. Pt (IV) prodrugs designed to bind non-covalently to human serum albumin for drug delivery. J Am Chem Soc. 2014; https://doi.org/10.1021/ja5038269.

10. Mayr J, Groza D, Galvez L, Koellensperger G, Roller A, Alte B, et al. An albumin-based tumor-targeted oxaliplatin prodrug with distinctly improved anticancer activity in vivo. Chem Sci. 2017; https://doi.org/10.1039/C6SC03862J.

11. Meermann B, Sperling M. Hyphenated techniques as tools for speciation analysis of metal-based pharmaceuticals: developments and applications. Anal Bioanal Chem. 2012; https://doi.org/10.1007/ s00216-012-5915-9.

12. Morris TT, Ruan Y, Lewis VA, Narendran A, Gailer J. Fortification of blood plasma from cancer patients with human serum albumin decreases the concentration of cisplatin-derived toxic hydrolysis products in vitro. Metallomics. 2014; https://doi.org/10.1039/ $\mathrm{c} 4 \mathrm{mt} 00220 \mathrm{~b}$.

13. Møller C, Tastesen HS, Gammelgaard B, Lambert IH, Stürup S. Stability, accumulation and cytotoxicity of an albumin-cisplatin adduct. Metallomics. 2010; https://doi.org/10.1039/c0mt00046a.

14. Brauckmann C, Wehe CA, Kieshauer M, Lanvers-Kaminsky C, Sperling M, Karst U. The interaction of platinum-based drugs with native biologically relevant proteins. Anal Bioanal Chem. 2013; https://doi.org/10.1007/s00216-012-6410-z.

15. Szpunar J. Advances in analytical methodology for bioinorganic speciation analysis: metallomics, metalloproteomics and heteroatom-tagged proteomics and metabolomics. Analyst. 2005; https://doi.org/10.1039/b418265k.

16. Timerbaev AR. Element speciation analysis using capillary electrophoresis: twenty years of development and applications. Chem Rev. 2013; https://doi.org/10.1021/cr300199v.

17. Vogiatzis CG, Zachariadis GA. Tandem mass spectrometry in metallomics and the involving role of ICP-MS detection: a review. Anal Chim Acta. 2014; https://doi.org/10.1016/j.aca.2014.01.029.

18. Ossipov K, Foteeva LS, Seregina IF, Perevalov SA, Timervaeb AR, Bolshov MA. Metallomics for drug development: serum protein binding and analysis of an anticancer tris(8-quinolinolato) gallium (III) drug using inductively coupled plasma mass spectrometry. Anal Chim Acta. 2013; https://doi.org/10.1016/j.aca.2013.05.004.

19. Bettmer J, Bayón MM, Encinar JR, Sánchez MS, de la Campa MF, Medel AS. The emerging role of ICP-MS in proteomic analysis. Proteomics. 2009; https://doi.org/10.1016/j.jprot.2009.05.003.

20. Holtkamp H, Hartinger CG. Advanced metallomics methods in anticancer metallodrug mode of action studies. TrAC Trends Anal Chem. 2017; https://doi.org/10.1016/j.trac.2017.09.023.

21. Sonet J, Bulteau A, Chavatte L, García-Barrera T, Gómez-Ariza JL, Callejón-Leblic B, Nischwitz V, Theiner S, Galvez L, Koellensperger G, Keppler BK, Roman M, Barbante C, Neth K, Bornhorst J, Michalke B Biomedical and pharmaceutical applications. In: Michaelke B, editor. Metallomics: analytical techniques and speciation methods. Wiley-VCH; 2016. pp: 359-462.

22. Groessl M, Terenghi M, Casini A, Elviri L, Lobinski R, Dyson PJ. Reactivity of anticancer metallodrugs with serum proteins: new insights from size exclusion chromatography-ICP-MS and ESIMS. J Anal At Spectrom. 2010; https://doi.org/10.1039/B922701F.

23. Hann S, Falta T, Boeck K, Sulyok M, Koellensperger G. On-line fast column switching SEC $x$ IC separation combined with ICP-MS detection for mapping metallodrug-biomolecule interaction. J Anal At Spectrom. 2010; https://doi.org/10.1039/c000427h.

24. Szpunar J, Makarov A, Pieper T, Keppler BK, Łobiński R. Investigation of metallodrug-protein interactions by sizeexclusion chromatography coupled with inductively coupled plasma mass spectrometry (ICP-MS). Anal Chim Acta. 1999; https:// doi.org/10.1016/S0003-2670(99)00074-4.

25. Pasch H, Kilz P. Fast liquid chromatography for high-throughput screening of polymers. Macromol Rapid Commun. 2003; https:// doi.org/10.1002/marc.200390005. 
26. Shi X, Tal G, Hankins NP, Gitis V. Fouling and cleaning of ultrafiltration membranes: a review. J Water Process Eng. 2014; https:// doi.org/10.1016/j.jwpe.2014.04.003.

27. Falta T, Heffeter P, Mohamed A, Berger W, Hann S, Koellensperger G. Quantitative determination of intact free cisplatin in cell models by LC-ICP-MS. J Anal At Spectrom. 2011; https://doi.org/10.1039/ C0JA00047G.

28. Timerbaev AR. Recent progress of ICP-MS in the development of metal-based drugs and diagnostic agents. J Anal At Spectrom. 2014; https://doi.org/10.1039/c3ja50394a.

29. Cunnigham J, Wang D, Wellner L, Li L. Investigation and reduction of sub-microgram peptide loss using molecular weight cut-off fractionation prior to mass spectrometric analysis. J Mass Spectrom. 2012; https://doi.org/10.1002/jms.3069.

30. Greening DW, Simpson RJ. A centrifugal ultrafiltration strategy for isolating the low-molecular weight $(\leq 25 \mathrm{~K})$ component of human plasma proteome. J Proteome. 2009; https://doi.org/10.1016/j.jprot. 2009.09.013.

31. Hermann G, Heffeter P, Falta T, Berger W, Hann S, Koellensperger G. In vitro studies on cisplatin focusing on kinetic aspects of intracellular chemistry by LC-ICP-MS. Metallomics. 2013; https://doi. org $/ 10.1039 / \mathrm{c} 3 \mathrm{mt} 20251 \mathrm{~h}$

32. Falta T, Koellensperger G, Standler A, Buchberger W, Mader RM, Hann S. Quantification of cisplatin, carboplatin and oxaliplatin in spiked human plasma samples by ICP-SFMS and hydrophilic interaction liquid chromatography (HILIC) combined with ICP-MS detection. J Anal At Spectrom. 2009; https://doi.org/10.1039/b907011g.

33. Couchman L. Turbulent flow chromatography in bioanalysis: a review. Biomed Chromatogr. 2012; https://doi.org/10.1002/bmc. 2769.

34. Mueller DM, Duretz B, Espourteille FA, Rentsch KM. Development of a fully automated toxicological LC-MSn screening system in urine using online extraction with turbulent flow chromatography. Anal Bioanal Chem. 2011; https://doi.org/10. 1007/s00216-010-4560-4.

35. Koellensperger G, Galanski M, Keppler BK, Hann S. Turbulent flow chromatography in combination with HPLC-ICP-MS for high-throughput analysis of free, intact metal based drugs in biomedical samples. J Anal At Spectrom. 2016; https://doi.org/10. 1039/C6JA00108D.

36. Xin GZ, Zhou JL, Qi LW, Li CY, Liu P, Li HJ, et al. Turbulent-flow chromatography coupled on-line to fast high-performance liquid chromatography and mass spectrometry for simultaneous determination of verticine, verticinone and isoverticine in rat plasma. $\mathrm{J}$ Chromatogr B Anal Technol Biomed Life Sci. 2010; https://doi. org/10.1016/j.jchromb.2009.12.027.

37. Popovici ST, Schoenmakers PJ. Fast size-exclusion chromatography - theoretical and practical considerations. J Chromatogr A. 2005; https://doi.org/10.1016/j.chroma.2005.08.071.

38. Gritti F, Guiochon G. Mass transfer kinetics, band broadening and column efficiency. J Chromatogr A. 2012; https://doi.org/10.1016/j. chroma.2011.04.058.

39. Bouvier ESP, Koza SM. Advances in size-exclusion separations of proteins and polymers by UHPLC. Trends Anal Chem. 2014; https://doi.org/10.1016/j.trac.2014.08.002.

40. Janco M, Iv JNA, Bouvier ESP, Morrison D. Ultra-high performance size-exclusion chromatography of synthetic polymers. J Spec Sci. 2013; https://doi.org/10.1002/jssc.201300444.

41. Uliyanchenko E, Schoenmakers PJ, Van Der Wal S. Fast and efficient size-based separations of polymers using ultra-high-pressure liquid chromatography. J Chromatogr A. 2011; https://doi.org/10. 1016/j.chroma.2011.01.053.

42. Mazzoni M, Polesello S, Rusconi M, Valsecchi S. Liquid chromatography mass spectrometry determination of perfluoroalkyl acids in environmental solid extracts after phospholipid removal and online turbulent flow chromatography purification. J Chromatogr A. 2016; https://doi.org/10.1016/j.chroma.2016.05.047.

43. Rezai T, Gvozdyak O, Prakash A, Athanas M, Lopez M. Investigation Into the Peptide Selectivity of TurboFlow Columns. 2010. http://www.thermofisher.co.nz/Uploads/file/Scientific/ Applications/Life-Science-Research-Technologies/InvestigationInto-the-Peptide-Selectivity-of-TurboFlow-Columns.PDF. 